\title{
Experimental Study on Mechanical Properties of Granite at Different Damage Degrees
}

\author{
Maotong Li \\ College of Water Conservancy and \\ Civil Engineering \\ Shandong Agricultural University \\ Tai' an City, China \\ Leemaotong@163.com \\ Yuanchao Zhou \\ College of Water Conservancy and \\ Civil Engineering \\ Shandong Agricultural University \\ Tai'an City, China \\ 1141224318@qq.com
}

\author{
Chuanxiao Liu \\ College of Water Conservancy and \\ Civil Engineering \\ Shandong Agricultural University \\ Tai' an City, China \\ Lchuanx@163.com
}

Jiashu Liang

College of Water Conservancy and

Civil Engineering

Shandong Agricultural University

Tai'an City, China

1358332400@qq.com

\author{
Huaqing Yang \\ College of Water Conservancy and \\ Civil Engineering \\ Shandong Agricultural University \\ Tai'an City, China \\ 752936051@qq.com
}

\begin{abstract}
Rock mechanics servo testing machine was used to test the uniaxial compression of granites with different degrees of damage. Based on the experimental results of stressstrain curves, the influence of different damage degrees on the mechanical properties of granite was analyzed. The results show that compared with intact granites, with the increase of damage degree, the mechanical properties of granites are obviously decreased. Their peak strengths and peak strains were significantly reduced, and the decrease was closely related to the degree of damage. As the damage degree reached $0.743 \%$, the peak strength of the rock samples decreased significantly, the decline amplitude gradually increased, and then the peak intensity decreased slowly. The greater the damage, the greater the damage effect, the peak strength of the granite is greatly reduced, and the peak strain of the rock sample is significantly reduced. When the damage degree is less than $0.513 \%$, the peak strain is greatly reduced. When the damage degree is higher than $0.513 \%$, the decrease in peak strain decreases gradually. As the degree of damage increases, the strength of the rock sample decreases, the initial crack closes in a shorter time and a new crack is immediately created, resulting in a gradual reduction in the strain at failure.
\end{abstract}

Keywords--rock mechanics, damage degree, granite, stressstrain curve, uniaxial compression, mechanical characteristics

\section{INTRODUCTION}

As a kind of complicated engineering medium, rock is composed of many defects such as joints, cracks and faults. These defects make the macroscopic deformation of rock under external load show obvious non-uniformity and discontinuity, anisotropic and non-elastic characteristics[1][5]. The engineering rock-like non-broken off, it seems even the non-connected, showing intermittent structural features. Numerous researches have shown that the spatial locations of joints, cracks, and faults (such as crack length, crack dip, and rock bridge length) contained in the engineering rock mass significantly affect their mechanical characteristics under external loads, affects the deformation and strength characteristics of the rock mass[6]-[15]. Therefore, studying the mechanical properties of rock under different damage degree has important theoretical and practical significance for ensuring the stability and safety of rock engineering.

Three-point bending method, cutting method, embedded chip method are commonly used to treat pre-crack cracks on rock samples. The three-point bending method imposes severe requirements on the crack carrier. The success rate of the application on the rock is low, and the crack length and tilt angle are not easy to control. The pre-made cracks on the rock plate are affected by the polycrystalline structure of the rock itself, and the prefabricated cracks. Not as flat as in a uniform material such as glass. Because of its simple method, the cutting method can be used to produce cracks of various inclination angles and lengths freely on rocks. However, the traditional circular cutters produce gaps of at least $0.6 \mathrm{~mm}$, which is clearly different from Griffith's definition of straight, extremely sharp ends and zero thickness cracks. The embedded sheet method is only applicable to cement and concrete, and cannot be implemented on the rocks. This article uses electroplated diamond wire saw to process cracks. It has the characteristics of continuous smooth cutting surface and narrow processing gap in the processing of hard and brittle materials. Compared with other methods, the cracks processed by electroplated diamond wire saw are closer to ideal cracks, and more adherence to fractures in natural rock mass[16]-[22].

Therefore, in this paper, rock specimens with different degrees of damage are obtained by prefabricating different depths of cracks in the granite, and the uniaxial compression test is carried out by using the servo testing machine to obtain the stress-strain curve, the effect of different damage degrees on the mechanical properties of granites and the variation of their mechanical properties were studied.

\section{TEST OVERVIEW}

\section{A. Test Specimen}

The test sample was taken from Shandong and the rock type was granite. The integrity of the rock samples was good. The main minerals were quartz and feldspar. When preparing a rock sample, it is processed in the same direction at the 
same position. At the same time, in order to ensure the authenticity and comparability of the test results, the appearance of the processed rock samples was carefully observed before the test, and it was confirmed that there were no obvious joints and cracks, so as to ensure that there was no obvious difference in macroscopic test samples. Using rock corers, cutters, and grinders, according to the requirements of the International Society of Rock Mechanics (ISRM), the rock samples were processed into 9 standard cylindrical specimens of diameter $50 \mathrm{~mm}$ and height $100 \mathrm{~mm}$, numbered 0-8,as shown in Fig.1.

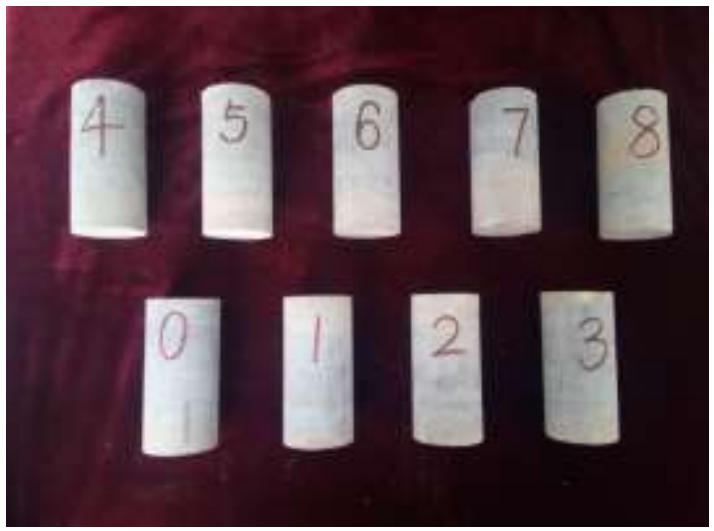

Fig.1. Initial granite specimens

In this experiment, nine rock specimens were processed using an electroplated diamond wire saw with a diameter of $0.4 \mathrm{~mm}$, and kerf processing was performed horizontally at a height of $1 / 2$ of each specimen. The initial depth of cut of the specimen was $3 \mathrm{~mm}$, and the depth of cut was increased in increments of $3 \mathrm{~mm}$. The maximum depth of cut was $24 \mathrm{~mm}$ less than the radius of the specimen $(25 \mathrm{~mm})$, which met the requirements. In order of increasing depth of cut, they are numbered 1-8, and sample 0 is used as a control without any treatment, as shown in Fig. 2.

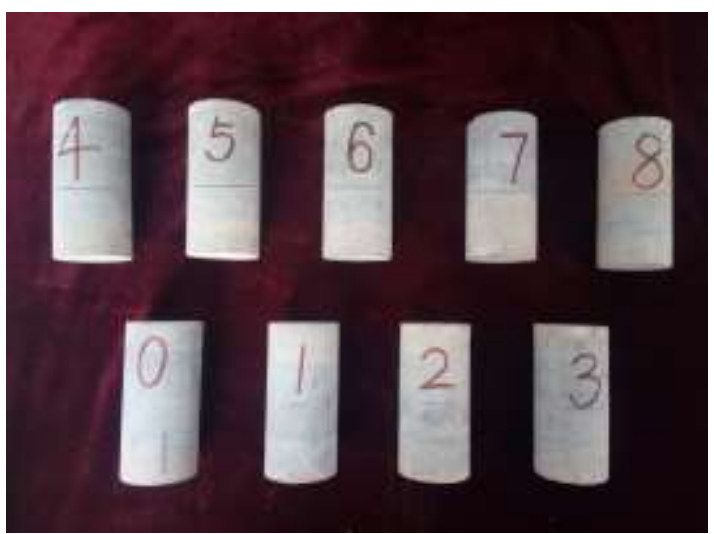

Fig.2. Treated granite specimens

\section{B. Damage Degree Calculation}

All rock samples were weighed using a DSJ-5 electronic balance, weighed before and after cutting, and the weighing quality was recorded. The damage degree of each sample (indicated by A) is calculated according to the formula by the mass number obtained by twice weighing each sample. Calculated as follows:

$$
A=\frac{m_{1}-m_{2}}{m_{1}} \times 100 \%
$$

Where: $A$ - degree of damage;

$$
\begin{aligned}
& \mathrm{m}_{1} \text { - initial quality, } \mathrm{g} ; \\
& \mathrm{m}_{2} \text { - processed quality, } \mathrm{g} .
\end{aligned}
$$

The damage calculation results for each specimen are shown in Table 1:

TABLE1 DAMAGE DEGREE CALCULATION RESUlT FOR EACH TEST PIECE

\begin{tabular}{|c|c|c|c|c|}
\hline Number & $\begin{array}{c}\text { Cutting } \\
\text { depth/mm }\end{array}$ & $/ \mathbf{g}$ & $/ \mathbf{g}$ & $\begin{array}{c}\text { Degree of } \\
\text { damage /\% }\end{array}$ \\
\hline 0 & 0 & 507.8 & 507.8 & 0 \\
\hline 1 & 3 & 500.7 & 500.4 & 0.060 \\
\hline 2 & 6 & 504.4 & 503.9 & 0.099 \\
\hline 3 & 9 & 511.5 & 510.5 & 0.196 \\
\hline 4 & 12 & 512.5 & 500.8 & 0.332 \\
\hline 5 & 15 & 506.7 & 504.1 & 0.513 \\
\hline 6 & 18 & 511.2 & 507.4 & 0.743 \\
\hline 7 & 21 & 497.6 & 492.4 & 1.045 \\
\hline 8 & 24 & 508.7 & 501.8 & 1.356 \\
\hline
\end{tabular}

\section{Test Equipment}

The SAW-2000 microcomputer-controlled electrohydraulic servo rock triaxial testing machine developed by Changchun Kexin Test Instrument Co., Ltd. configured in the Water Conservancy Civil Engineering Experimental Center of Shandong Agricultural University,It is mainly used for uniaxial compression tests, triaxial compression tests, relaxation tests, and low-period pulsation tests of rock, concrete, and cement mortar specimens.Three sets of DOLI company's EDC controller and MOOG's D633 proportional servo valve were used to complete the whole process of the experiment, achieving automatic control and data acquisition. The stiffness of the testing machine reaches $2 \times 10^{10} \mathrm{~N} / \mathrm{m}$, and the response frequency is fast, which can fully meet the mechanical test requirements of concrete specimens. Samples and test equipment are shown in Fig. 3.

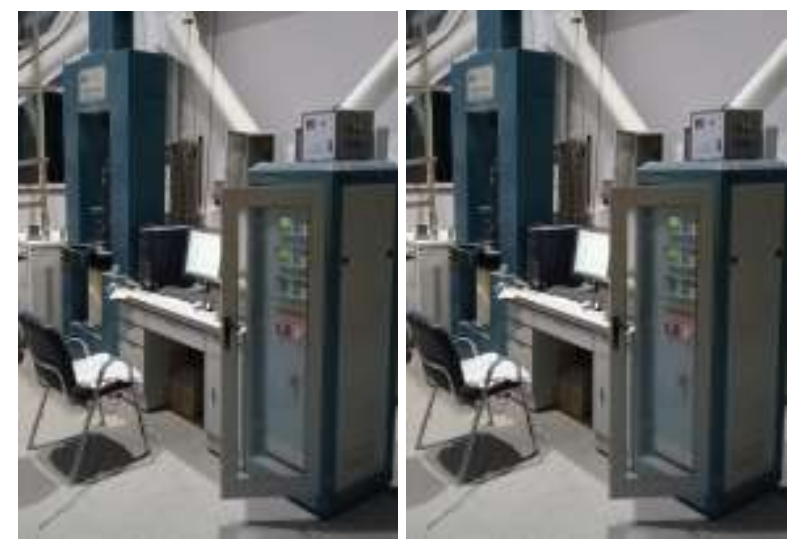

Fig.3. Rock specimen and Test Equipment

\section{Test Results and Analysis}

\section{1) Test results}

The uniaxial compression test was performed on each granite specimen to obtain the stress-strain curve. The mechanical parameters of each specimen were calculated and 
calculated. The Origin8.5.1 were used to summarize the mechanical parameters of each rock specimen and then analyzed. The variation of mechanical properties of granite specimens under different damage degrees was obtained.

The axial stress-strain curve of granite under different damage degree obtained by servo testing machine is shown in Fig.4. It can be seen from Fig. 4 that with the increase of the damage degree, the stress-strain curve of the granite specimen has obvious changes, and both the peak strength and the peak strain are significantly reduced.

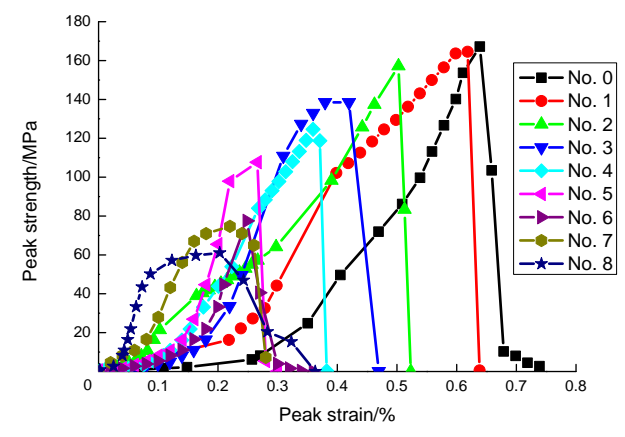

Fig.4. Stress-strain curves for each specimen

\section{2) Analysis of test results}

For rock specimens of different damage degrees, the stress-strain relationship under uniaxial compression can be divided into four stages: the micro-crack closure stage, the elastic deformation to the micro-fracturing stable development stage, the fissure non-steady development and destruction stage, and the post-failure stage .

The variation of the peak intensity of granite under different degrees of damage is shown in Fig. 5.

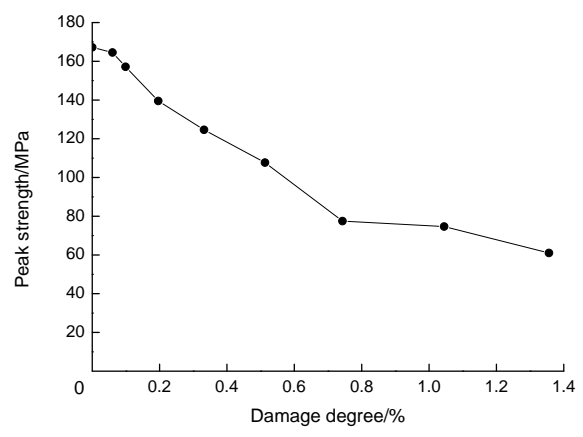

Fig.5. The variation of the peak intensity of granite under different degrees of damage

By analyzing the variation rule of granite peak strength under different damage degree, the peak strength of granite specimen gradually decreases with the increase of damage degree. With the increase of cutting depth, the damage degree was $0,0.06 \%, 0.99 \%, 0.196 \%, 0.332 \%, 0.513 \%$, $0.743 \%, 1.045 \%, 1.356 \%$. The peak intensity of the test specimens decreased by $1.60 \%$ and $4.47 \%$ in turn. $11.24 \%$, $10.66 \%, 13.59 \%, 28.03 \%, 3.64 \%, 18.29 \%$. When the damage degree is less than $0.743 \%$, the peak strength of the specimen decreases more significantly; after $0.743 \%$, the peak intensity decreases slowly.
The variation of peak strain of granite under different damage degree is shown in Fig.6.

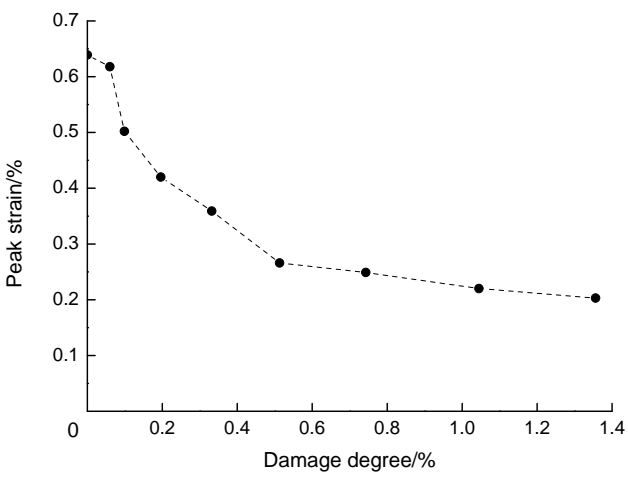

Fig.6. The variation of peak strain of granite under different damage degree

By analyzing the variation rule of granite peak strain under different damage degree, the peak strain of granite specimen gradually decreases with the increase of damage degree. With the increase of cutting depth, the damage degree was $0,0.06 \%, 0.99 \%, 0.196 \%, 0.332 \%, 0.513 \%$, $0.743 \%, 1.045 \%, 1.356 \%$. The peak strain of the specimen decreased by $3.29 \%$ and $18.77 \%$. $16.33 \%, 14.52 \%, 25.91 \%$, $6.39 \%, 11.65 \%, 7.73 \%$. When the damage degree is lower than $0.513 \%$, the peak strain of the specimen decreases greatly, and after $0.513 \%$, the decrease amplitude gradually decreases.

\section{MAIN CONCLUSIONS}

With the increase of damage degree, the mechanical properties of granite have changed significantly, and its peak strength and peak strain have been significantly reduced, and the magnitude of reduction is closely related to the magnitude of damage.

Compared with the intact granite without fracture, with the damage degree reaching $0.743 \%$, the peak strength of the rock sample decreases obviously, and the decreasing extent increases gradually. At this point the cutting depth has reached $18 \mathrm{~mm}$, which is more than $2 / 3(16.7 \mathrm{~mm})$ of the rock sample radius, after which the peak intensity slowly decreases. When the depth of cut reaches $24 \mathrm{~mm}$ and the damage degree reaches $1.356 \%$, the peak strength of the rock sample is only $36.50 \%$ of the intact granite without cracks. The development of rock cracks causes stress concentration effects. The cracks first break down in some weak parts and redistribute the stress. As a result, the new weak parts are destroyed, and the test pieces are completely destroyed. The greater the degree of damage, the more significant the damage effect, which seriously reduces the compressive strength of granite.

With the increase of damage degree, the peak strain of rock sample decreases significantly. Before the $0.513 \%$ damage degree, the peak strain decreases greatly; after the damage degree exceeds $0.513 \%$, the peak strain of the rock sample slowly decreases. . In a uniaxial compression test of a rock specimen with a certain degree of damage, the originally existing cracks in the rock are closed or compacted first, and the pores are compressed, and new cracks are 
generated as the stress increases. The deformation mainly manifests as plastic deformation due to the generation of new fractures. As the degree of damage increases, the strength of the rock sample decreases, the initial crack closes in a shorter time and a new crack is immediately generated, resulting in a gradual reduction in the strain at failure.

\section{ACKNOWLEDGMENT}

This paper finished under the guidance of tutor Liu Chuanxiao, and was supported by the Key Research and Development Project of Shandong Province (No. 2018GNC110023), the Natural Science Foundation of Shandong Province (No. ZR2014DM019) and the National Natural Science Foundations of China (No. 51574156, 51004098).

\section{REFERENCES}

[1] Sun Jun, Rheology and Engineering Application of Geotechnical Materials, Beijing: China Construction Industry Press, 1999.

[2] He Manchao, Jing Haihe, and Sun Xiaoming, Soft Rock Engineering Mechanics, Beijing: Science Press, 2002.

[3] Li Shulin,Yi Xiangang, Wang Yongjia, "Studies on acoustic emission characteristics of uniaxial compressive rock failure",Chinese Journal of Rock Mechanics and Engineering, vol. 23, pp.2499-2503, February ,2003.

[4] Huang Mingli, Tang Chun'an, Zhu Wancheng, "Real-time SEM study on rock failureinstability under uniaxial compression",Journal of Northeastern University(Natural Science), vol. 20, pp.426-429,1999.

[5] Qin Yueping,Sun Wenbiao, Wang lei,"Analysis on damage mechanics model of rock",Chinese Journal of Rock Mechanics and Engineering, vol 22, pp. 702-705, April ,2003.

[6] Jiang Yongdong, Xian Xuefu, Xu Jiang, "A research on sandstone uniaxial and triaxial compression tests",China Mining, vol 13, pp. 6669, May ,2004.

[7] Chen Weizhong,Li Shucai,Zhu Weishen,"Experimental and numerical research on crack propagation n rock under compression", Chinese Journal of Rock Mechanics and Engineering, vol 22, pp. 1823, January ,2003.

[8] Jiang Mingjing, Chen He, "Distinct element analysis of crack propagation in rocks containing pre-existing single flaws", Chinese Journal of Rock Mechanics and Engineering,under review.

[9] Cai Meifeng, He Manchao,Liu Dongyan, "Rock mechanics and engineering",Beijing: Science Press,2002.

[10] Zhang Ning,Zhang Ping,Chen Yunsheng.Study development and thinking for experiment of crack body [C]//The seventh academic congress symposium of Chinese society for rock mechanics and engineering in China. Xi'an:Science and Technology of China Press, 2002.

[11] Bobet A. "The initiation of secondary cracks in compression", Engineering Fracture Mec;hanics, vol 66, pp.187-219, February ,2006

[12] Sagong M, Bobet A. "Coalescence of multiple flaws in a rock-model material in uniaxial compression",International Journal of Rock Mechanics and Mining Sciences, vol 39, pp. 229-241, February ,2002.

[13] Park C H, Bobet A, "Crack coalescence in specimens with open and closed flaws:A comparison",International Journal of Rock Mechanics and Mining Sciences, vol 46, pp. 818-829, May,2009.

[14] Wong R H C, Lin P, Tang C A. "Experimental and numerical study on splitting failure of brittle solids containing single pore under uniaxial compression",Mechanics of Materials, vol 38, pp 142-159, January ,2006.

[15] Khanal M, Schubert W, Tomas J. "Compression and impact loading experiments of high strength spherical composites", International Journal of Mineral Processing, vol 86, pp. 104-113, March ,2008.

[16] BOBET A, EINSTEIN H H. "Fracture coalescence in rock-type materials under uniaxial and biaxial compression", International Journal of Rock Mechanics and Mining Sciences, vol 35, pp. 863-888, July, 1998 .

[17] SHEN B, "The mechanism of fracture coalescence in compressionexperimental study and numerical simulation",Engineering Fracture Mechanics, vol51, pp. 73-85, January ,1995.
[18] EBERHARDT E. STEAD D,STIMPSON B, "The effect of neighbouring cracks on elliptical crack initiation and propagation in uniaxial and triaxial stress fields",Engineering Fracture Mechanics, vol 59, pp. 103-115, February, 1998.

[19] WONG R H C,CHAD K T,TANG C A, "Analysis of crack coalescence in rock-like materials containing three flaws-part I:experimental approach",International Journal of Rock Mechanics and Mining Sciences, vol 38, pp. 909-924, July,2001.

[20] TANG C A,LIN P. WONG R H C, "Analysis of crack coalescence in rock-like materials containing three flaws-part II:numerical approach",International Journal of Rock Mechanics and Mining Sciences, vol 38, pp. 925-939, July,2001.

[21] TANG C A, "Numerical simulation of progressive rock failure and associated seismicity",International Journal of Rock Mechanics and Mining Sciences, vol 34, pp. 249-262, February ,1997.

[22] ZHAO Y H., "Crack pattern evolution and a fractal damage constitutive model for rock",International Journal of Rock Mechanics and Minining Sciences, vol 35, pp. 349-366, March ,1998. 